\title{
Open vs laparoscopic repair of abdominal hernia: a case control study in over 60 years old patients
}

\author{
Massimiliano Fabozzi ${ }^{1}$, Rosaldo Allieta', Luciano Grimaldi' ${ }^{2}$ Stefano Reggio ${ }^{2}$, Bruno Amato ${ }^{2}$, Michele Danzi ${ }^{2 *}$ \\ From 26th National Congress of the Italian Society of Geriatric Surgery \\ Naples, Italy. 19-22 June 2013
}

\section{Background}

About $15 \%$ of patients who have been undergone to a laparotomy may develope abdominal wall hernia and the risk increases with age. In last years the Laparoscopic treatment of ventral hernia (LVHR) is becoming increasingly widespread in surgical community thanks to the good outcomes of this technique [1,2]. The aim of this study was to describe the experience of our surgical centers in order to establish the safety, efficacy, and feasibility of LVHR using composite mesh and tacks (Figure 1) compared to the open technique (OVHR).

\section{Methods}

Between January 2001 and March 2013, 523 patients were admitted to the Specialistic Surgery Centers (Aosta "U. Parini Hospital and Naples "Federico II" Hospital) and treated for abdominal wall hernia. Two groups (Open and Laparoscopic Repair), each one of 100 patients, with similar characteristics have been selected from these(mean age, sex, BMI, ASA risk and for type and size of surgical defects, Table 1): the first group was treated by laparoscopic repair and the second by open hernia repair. Mean age was 66 years old (range: 60-72) in open group and 68 years old (range: 63-73) in Laparoscopic group. Study outcomes were : operative time, complications, postoperative pain, analgesic therapy duration, intestinal function restoration, mean hospital stay, mortality and rate of recurrence at oneyear follow-up.

* Correspondence: michele.danzi@unina.it

${ }^{2}$ Department of Specialized Surgery, Division of Gastrointestinal Surgery Rehabilitation of Election and Emergency. "Federico II" University, Naples, Italy

Full list of author information is available at the end of the article

\section{Results}

Outcomes data are shown in Table 2 . In LVHR group the $55 \%$ of patients presented incisional hernia and $45 \%$ epigastric or umbilical hernias. In OVHR group the $52 \%$ of patients presented incisional hernia and $48 \%$ epigastric or umbilical hernias. The mean size of surgical defects was $11.4+9.7 \mathrm{~cm}$ in Laparoscopic group and $12.6+9.2 \mathrm{~cm}$ in Open group. Mean operative time was $61+22 \mathrm{~min}$ in Laparoscopic group and $105+27 \mathrm{~min}$. The post-operative complications rate was $14 \%$ in Open group and 5\% in Laparoscopic group. Patients who underwent LVHR presented a more rapid restoration of intestinal function, less

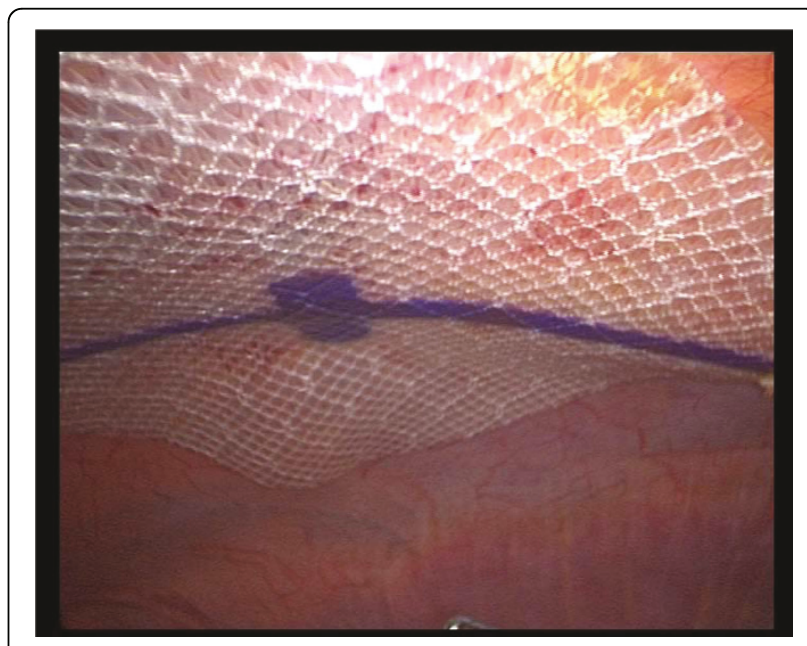

Figure 1 intraoperative image Laparoscopic repair of incisional hernia.

(C) 2013 Fabozzi et al; licensee BioMed Central Ltd. This is an Open Access article distributed under the terms of the Creative Commons 
Table 1 Patients data and operative parameters

\begin{tabular}{lcc}
\hline & Open abdominal wall hernia repair & Laparoscopic abdominal wall hernia repair \\
\hline Patients number & 100 & 100 \\
Age (years) & $65.4 \pm 4.5$ & $67.7 \pm 3.1$ \\
Sex & $56 \mathrm{~F} / 44 \mathrm{M}$ & $49 \mathrm{~F} / 51 \mathrm{M}$ \\
BMI $\left(\mathbf{k g} / \mathbf{m}^{2}\right)$ & $27.1 \pm 1.9$ & $29.3 \pm 3.6$ \\
Asa $\mathbf{i}$ & 43 & 32 \\
Asa ii & 47 & 49 \\
Asa iii & 10 & 19 \\
Wall defects size $(\mathbf{c m})$ & $12.6 \pm 9.2$ & $11.4 \pm 9.7$ \\
Ng tube removal & after the operation & after the operation \\
Urinary catheter removal & evening of surgery & operation (only in parapubic repair) \\
Water assumption & evening of surgery & 1 of surgery
\end{tabular}

Table 2 Outcomes

\begin{tabular}{lcc}
\hline Outcomes & Open abdominal wall hernia repair & Laparoscopic abdominal wall hernia repair \\
\hline Operative time (min.) & $105 \pm 27$ & $61 \pm 22$ \\
Intra-operative complications & 0 & 0 \\
Laparotomy size (cm) & $16 \pm 7$ & No \\
First peristalsis (days) & $2.1 \pm 0.9$ & $1.1 \pm 0.7$ \\
First defecation (days) & $3.1 \pm 1.6$ & $1.6 \pm 1.3$ \\
Permanence of drain (days) & $2.3 \pm 1.6$ & No \\
Post-operative pain (VAS pain scale) & 6.6 & 1.7 \\
Anesthetic tap block & No & $1.1 \pm 1.5$ \\
Analgesic duration terapy(days) & $4.8 \pm 1.5$ & $5(5 \%)$ \\
Post-operative complications (number, rate) & $14(14 \%)$ & $1.9 \pm 1.8$ \\
Hospital stay (days) & $5.6 \pm 1.2$ & 0 \\
Mortality & 0 &
\end{tabular}

Table 3 Complications

\begin{tabular}{lcc}
\hline & Open abdominal wall hernia repair & Laparoscopic abdominal wall hernia repair \\
\hline Hematoma & $6 \%$ & $1 \%$ \\
Seroma & $4 \%$ & $3 \%$ \\
Visceral lesions & 0 & 0 \\
Sub-occlusion & 0 & 0 \\
Respiratory infections & $1 \%$ & 0 \\
Infections of prosthesis & 0 & 0 \\
Fascial necrosis & 0 & 0 \\
Postop. Pain (6 mesi) & $3 \%$ & $1 \%$ \\
Recurrence & $7 \%$ & $4 \%$ \\
Mortality & 0 & 0
\end{tabular}

postoperative pain and subsequently shorter analgesic therapy compared with the OVHR group. Postoperative complication rate is higher in the OVHR than LVHR group but the mortality rate was $0 \%$ for both tecniques. Mean hospital stay expressed in days is significantly reduced in LVHR. At one-year follow-up, we observed 7\% in OVHR vs $4 \%$ in LVHR of hernia recurrence.

\section{Conclusions}

LVHR is an effective and safe procedure with very low morbidity and recurrence rates $[3,4]$. It is associated with less postoperative pain and respiratory complications in over 60 years old patients thanks to less p.o. pain that doesn't compromise the diaphragmatic respiratory movements [5]. 
By our experience and the datas of Literature we can conclude that the Laparoscopic treatment of abdominal wall hernias (Incisional and not) presents more advatages compared to Open procedures related to reduced global complications and hospital stay with better comfort of patients.

\section{Authors' details}

'Department of General Surgery . "U. Parini" Hospital, Aosta, Italy. ${ }^{2}$ Department of Specialized Surgery, Division of Gastrointestinal Surgery Rehabilitation of Election and Emergency. "Federico II" University, Naples, Italy.

Published: 16 September 2013

\section{References}

1. Itani KMF, Hur K, Kim L, Anthony T, Neumayer L: Comparison of laparoscopic and open repair with mesh for the treatment of ventral incisional hernia. Arch Surg 2010, 145(4):322-8.

2. Eker HH, Hansson BM, Buunen M, Janssen IM, Pierik RE, Hop WC, Bonjer HJ, Jeekel J, Lange JF: Laparoscopic vs. open incisional hernia repair: a randomized clinical trial. JAMA Surg 2013, 148(3):259-63.

3. Amato B, Moja L, Panico S: Shouldice technique versus other open techniques for inguinal hernia repair (Review). Cochrane database of systematic reviews (online) 2012, 4:CD001543.

4. Cuccurullo D, Piccoli M, Agresta F, Magnone S, Corcione F, Stancanelli V, Melotti G: Laparoscopic ventral incisional hernia repair: evidence-based guidelines of the first Italian Consensus Conference. Hernia 2013.

5. Rea R, Falco P, Izzo D, Leongito M, Amato B: Laparoscopic ventral hernia repair with primary transparietal closure of the hernia defect. BMC Surgery 2012, 12(Suppl.1):S5.

doi:10.1186/1471-2482-13-S1-A19

Cite this article as: Fabozzi et al:: Open vs laparoscopic repair of abdominal hernia: a case control study in over 60 years old patients. BMC Surgery 2013 13(Suppl 1):A19.

\section{Submit your next manuscript to BioMed Central and take full advantage of:}

- Convenient online submission

- Thorough peer review

- No space constraints or color figure charges

- Immediate publication on acceptance

- Inclusion in PubMed, CAS, Scopus and Google Scholar

- Research which is freely available for redistribution

Submit your manuscript at www.biomedcentral.com/submit
C Biomed Central 